\title{
Moderate Intensity Training By Listening To Music Decreases Interleukin-6 Levels In Rats
}

\author{
Septyaningrum Putri Purwoto ${ }^{1}$, Adi Pranoto ${ }^{2}$, Hartono $^{3}$ and Sugiharto $^{3 *}$ \\ ${ }^{I}$ STKIP PGRI Bangkalan, East Java, Indonesia \\ ${ }^{2}$ Universitas Airlangga, Surabaya, East Java, Indonesia \\ ${ }^{3}$ State University of Malang, East Java, Indonesia \\ sugiharto@um.ac.id
}

\begin{abstract}
Decreasing levels of interleukin-6 (IL-6) is one of decrease inflammation indicators. This study aims to analyze the decrease of IL-6 serum levels in moderate and high intensity training by listening to music. The design of this study is the randomized control group posttest-only design, 21 of Rattus Norvegicus Strain Wistar male, 20-24 weeks, $250 \pm 350$ grams and randomly divided into 3 groups namely CONT $(\mathrm{n}=7$, control without treatment), MIT ( $\mathrm{n}=7$, moderate intensity training, treadmill with speed $14-16 \mathrm{~m} / \mathrm{min}$ for 15-30 minutes listening to music tempo 160 beats/min) and HIT ( $\mathrm{n}=7$, high intensity training, treadmill with speed $22-25 \mathrm{~m} / \mathrm{min}$ for $15-30$ minutes listening to music tempo 160 beats/min). The intervention was started from 17.00-20.00 WIB with a frequency of 3 times / week for 10 weeks. Blood is drawn for 12 hours after the last training. Measurement of IL-6 serum levels using the ELISA method. Data analysis techniques using ANOVA test and LSD post hoc test with the Statistical Package for Social Science (SPSS). The results obtained IL-6 levels at CONT $(1478,357 \pm 495,209) \mathrm{pg} / \mathrm{mL}$, MIT $(850,500 \pm 458,666) \mathrm{pg} / \mathrm{mL}$, HIT $(1756,928 \pm 467,793) \mathrm{pg} / \mathrm{mL}$ and $(\mathrm{p}=0.007)$. Based on the results of the study, it can be concluded that moderate intensity training by listening to music tempo 160 beats / min decreases IL-6 levels.
\end{abstract}

Keywords: Moderate Intensity Training, High Intensity Training, Fast Tempo Music, IL-6 Levels 


\section{STRADA Jurnal Ilmiah Kesehatan}

DOI: $10.30994 /$ sjik.v9i1.272

ISSN: 2252-3847 (print); 2614-350X (online)

Vol.9 No.1. May 2020. Page.93-101

\section{INTRODUCTION}

Exercise is an interesting and enjoyable activity; it's not only have an impact on improving health, physical and physiological conditions, but also psychological (Sugiharto, 2012). In addition, exercise also has beneficial effects for the central nervous system (Ahmadiasl et al., 2014), cardiovascular system (Mueller, 2007; Petersen and Pedersen, 2005), inhibits aging (Chung and Diffee, 2012) and prevents upper respiratory tract infection (URTI) (Nieman, 2012). Exercise effectively has a positive impact because exercise provides antiinflammatory effects (Moylan et al., 2013), treatment of chronic heart disease, diabetes mellitus type 2 and symptoms related to metabolic syndrome, so exercise is often used as an approach to improve and maintain physical as well as health (Lee and Paffenbarger, 2000; Kisan et al., 2012). However, training also has an ambiguous nature which can have a negative impact (Sugiharto, 2012). This has not been widely understood by sports practitioners and the society.

Exercise has a dual function for the body, because exercise can be a stressor, which has the potential to cause distress, otherwise exercise can be also stimulator that can cause eustress (Sugiharto, 2012). It really depends on the dose of exercise that is done. Exercise that is done with the proper dose can be a stimulator for the body, while exercise with heavy and competitive doses can be a stressor for the body (Mastorakos et al., 2005; Sugiharto, 2012). Stressors that occur in the body are not only physical stressors but also chemical, psychological and physiological stressors (Uchakin et al., 2003), which are caused by heavy exercise doses. This is because heavy doses of exercise cause inflammation that is caused by muscle damage (Glesson, 2005). Inflammation is a stressor involving the Hypothalamic Pituitary Adrenal-axis (HPA-axis) and the immune system (Moylan et al., 2013) which is characterized by cytokine secretion (Shaikh, 2011; Pedersen et al., 2001). Cytokines are inflammatory mediators, such as tumor necrosis factor- $\alpha$ (TNF- $\alpha$ ), interferon- $\gamma$ (IFN- $\gamma$ ), interleukin-1 (IL-1), interleukin-6 (IL-6), radical oxygen and substances other pro-inflammatory found in blood circulation (Indra, 2007). IL-6 is an increased cytokine in response to exercise (Mohammadi et al., 2012), IL-6 secretion precedes secretion from other cytokines (Febbraio and Pedersen, 2002; Petersen and Pedersen, 2006) and is a major cytokine that plays a central role in immune stimulation especially in inflammatory stress (Tsigos and Chrousos, 2002). Therefore, stress experienced must be managed properly; one method that is very effective and efficient in reducing stress is by listening to music (Sugiharto, 2009). This is because listening to music can increase enthusiasm during exercise so that it can improve health, fitness and achievement and the use of music consistently can reduce the occurrence of stress (Stefano, 2004). According to Chanda and Levitin (2013) explains that music is used to regulate mood and passion in everyday life and to improve physical and psychological health. Music is not just an auditif issue that is played through both ears, but it involves many aspects that are far more basic and profound (Djohan, 2010) and have the ability to capture attention, stimulate enthusiasm, produce emotions, change or regulate moods, evoke memories, enhance work output, reduce barriers and encourage rhythmic movements which all have potential applications in training (Terry and Karageorghis, 2006).

Research by Stefano et al. (2004) said that IL-6 levels decreased significantly due to Listening to music, but when exercise caused an increase in proinflammatory cytokines TNF- $\alpha$ and IL- $1 \beta$ and caused a dramatic increase in responsive inflammation of the IL-6 cytokine responsiveness if performed with heavy doses (Ostrowski et al., 1999). Likewise 


\section{STRADA Jurnal Ilmiah Kesehatan}

DOI: $10.30994 /$ sjik.v9i1.272

in the research of Zhang et al. (2007) that IL-6 increased due to heavy exercise dose, not only that the Bruce test exercise caused a significant increase in serum IL-6 and IL-33 levels after training compared to before training in volleyball athletes (Ali, 2014), during training 30 minutes with an intensity of $65 \%-70 \%$ of maximal oxygen uptake (VO2max) also significantly increased IL-6 levels (Mohammadi, 2011), moderate exercise for 45 minutes with an intensity of 50\% VO2max increased IL-6 levels (Shojaei et al. , 2011), exercise for 12 months reduces levels of IL-6 (Oberbach, 2008). Other researchers found an increase in IL-6 levels after 2 hours of eccentric training, but did not occur in concentric exercises (Bruunsgaard et al., 1997). Lyngso (2002) found the same thing with moderate exercise for 60 minutes, heavy doses of exercise caused an increase in proinflammatory cytokines TNF- $\alpha$ and IL- $1 \beta$ and caused a dramatic increase in inflammatory responsive cytokine IL-6 (Ostrowski et al., 1999) On the contrary, moderate-dose exercise can significantly reduce IL-6 (Starkweather, 2007). Based on the background of the problem above, the purpose of this study is to analyze the decrease in serum IL-6 levels in moderate and high intensity exercise by listening to music.

\section{METHODS}

\section{Research design}

The design of this study is the randomized control group posttest-only design, 21 of Rattus Norvegicus Strain Wistar male, 20-24 weeks, $250 \pm 350$ grams and randomly divided into 3 groups namely CONT ( $n=7$, control without treatment), MIT $(n=7$, moderate intensity training, treadmill with speed $14-16 \mathrm{~m} / \mathrm{min}$ for 15-30 minutes listening to music tempo 160 beats / $\mathrm{min}$ ) and HIT ( $\mathrm{n}=7$, high intensity training, treadmill with speed 22-25 m / min for 15-30 minutes listening to music tempo 160 beats / min).

\section{Exercise Protocol}

Moderate intensity exercise is done by rats running on a treadmill with a speed of 14-16 m / min for 15-30 minutes by listening to music tempo 160 beats / min whereas, high intensity exercise with a speed of 22-25 m/ min for 15-30 minutes by listening to music tempo 160 beats / min. The intervention was carried out at 17.00-20.00 WIB with a frequency of 3 times / week for 10 weeks.

\section{Blood analysis}

Blood is drawn from the left ventricle of experimental animals as much as $5 \mathrm{ml}$. Blood drawn 12 hours after the last exercise. Measurement of IL-6 levels using ELISA kit (Catalog No. E-EL-R0015; Elabscience, Inc., China, 2018) with a unit of concentration of $\mathrm{pg} / \mathrm{mL}$.

\section{Statistical Analysis}

Statistical analysis is using packet statistics for social science (SPSS) software (Chicago, IL, USA). The normality test uses the Shapiro-Wilk test, while the homogeneity test uses the Levene test. Data that are normally distributed and have a homogeneous variant are tested using the ANOVA test and continued with the post hoc LSD test with a significant level $(\mathrm{p}<0.01)$. All data are displayed with mean \pm SD.

\section{RESULTS}

The results of data analysis of average IL-6 levels after MIT and HIT intervention for 10 weeks can be seen in table 1 . 


\section{STRADA Jurnal Ilmiah Kesehatan}

DOI: $10.30994 /$ sjik.v9i1.272

ISSN: 2252-3847 (print); 2614-350X (online)

Vol.9 No.1. May 2020. Page.93-101

Table 1. Average IL-6 levels after MIT and HIT intervention

\begin{tabular}{cccc}
\hline Kelompok & $\mathbf{N}$ & $\begin{array}{c}\text { Mean } \pm \text { SD } \\
(\mathbf{p g} / \mathbf{m L})\end{array}$ & $\begin{array}{c}\text { ANOVA } \\
\mathbf{p}-\text { values }\end{array}$ \\
\hline CONT & 7 & $1478.357 \pm 495.209^{\mathrm{a}}$ & \\
\hline MIT & 7 & $850.500 \pm 458.666^{\mathrm{b}}$ & $0.007^{*}$ \\
\hline HIT & 7 & $1756.928 \pm 467.793^{\mathrm{a}}$ & \\
\hline
\end{tabular}

Note: Different superscripts indicate that there are significant differences in the LSD post hoc test with $(\mathrm{p}<0.01)$.

Based on table 1 it can be seen that the IL-6 level at MIT is lower than that of HIT and CONT. Based on ANOVA test results showed that there were significant differences in the average levels of IL-6 ( $\mathrm{p}=0.007)$. Based on the LSD post hoc test, there was a significant difference in IL-6 levels between MIT and CONT ( $p=0.023)$, MIT and HIT $(p=0.002)$, while HIT with CONT were no significant differences $(\mathrm{p}=0.286)$, but based on the value the average IL-6 level in HIT tends to be higher than the average CONT value.

\section{DISCUSSION}

This study aims to analyze the decrease in serum IL-6 levels in moderate and high intensity training by listening to music. The novelty of our method is the use of music tempo 160 beats/ min. To meet these objectives, we combine moderate and high intensity exercise with listening to music tempo 160 beats / min. Based on the results of the study, it is showed that IL-6 levels at MIT were lower than those of HIT and CONT.

Based on the results of the study, it is showed that there were significant differences in IL6 levels between MIT and CONT $(\mathrm{p}=0.023)$. These results are in line with the results of a study conducted by Stefano et al. (2004) concluded that IL-6 levels decreased significantly after listening to music, as well as after moderate-intensity training for 12 months significantly reduced IL-6 levels (Oberbach, 2008). Research conducted by (Starkweather, 2007) found similar results that moderate intensity exercise lowers IL-6 levels. However, these results are different from the study results that are conducted by Markovitch et al. (2008) he is concluded that IL-6 levels increased significantly after doing moderate intensity exercise. This study conducted by Mohammadi (2011) found similar results those 30 minutes of exercise with an intensity of $65 \%-70 \%$ VO2max also significantly increased IL-6 levels. This difference caused by the use of music tempo 160 beats / min for this study, whereas in previous studies did not use music. This is possible because the use of music tempo 160 beats / min in this study affects the decrease in IL-6 levels. According to the results of research conducted by Okada (2008) concluded that exercise by listening to music reduces levels of IL-6. The combination of exercise with music can affect the body's physiology, this is because various musical features, namely rhythm, tempo and genre can increase energy tolerance through distraction and increase comfort (Savitha et al., 2013) and reduce muscle fatigue during exercise (Bakhtiar et al., 2012). In addition, exercise by listening to music can also reduce stress responses which are marked by a decrease in cortisol secretion (Sugiharto, 2009). Decreased cortisol secretion will reduce the secretion of IL-6 (Daloii et al., 2014), so that moderate intensity exercise by listening to music can be a stimulator for the body which has the potential to cause antiinflammatory effects for the body (Moylan et al., 2013) which has an impact on increasing 


\section{STRADA Jurnal Ilmiah Kesehatan}

DOI: $10.30994 /$ sjik.v9i1.272

ISSN: 2252-3847 (print); 2614-350X (online)

Vol.9 No.1. May 2020. Page.93-101

the quality of physical, psychological and health conditions (Sugiharto, 2009; Sugiharto, 2012).

There was a significant difference in IL-6 levels between MIT and HIT ( $p=0.002)$. This difference is due to the treatment of MIT and HIT. Although MIT and HIT were given the same music, the influence of MIT and HIT gave different responses to IL-6 levels. According to Neto et al. (2016) that exercise is a strategy in reducing the inflammatory process. In addition, exercise is also considered as stressor. If exercise is considered as stressor, the body will react by increasing awareness of threats that can interfere with homeostasis. The threat signal will be responded by the body with the mechanism of general adaptation syndrome or GAS (Sugiharto, 2012), but exercise is also considered a stimulator. According to (Mastorakos \& Pavlatou, 2005) HIT becomes a stressor for the body, otherwise exercise as a stimulator when it is done with MIT. This is likely due to the MIT coping mechanism. The coping mechanism is the body's effort to fight the pressure, so that it gradually adapts to stress, so that it feels "good" in the face of shock, then a higher adaptation occurs (Rushall \& Pyke in Sugiharto, 2012). At MIT, cortisol secretes to make adaptation mechanisms to stress (Sugiharto, 2012), with the result that cortisol secretion is lower which triggers a decrease in IL-6 (Daloii et al., 2014). This is similar to previous study conducted by (Sugiharto, 2009) that listening to music in submaximal intensity exercises tends to decrease cortisol secretion. So MIT can be a stimulator for the body (Sugiharto, 2012).

ANOVA test results (Table 1) showed that there was no significant difference in IL-6 levels between HIT and CONT $(\mathrm{p}=0.286)$. However, when it is viewed from the average value of HIT, it tends to have higher IL-6 levels compared to CONT. These results are in line with the results of a study conducted by Eaton et al. (2018) concluded that highintensity interval training (HIIT) caused an increase in IL-6 levels of $\sim 25$-fold and 3 hours after the intervention there was an increase of 30-fold. High levels of IL-6 in HIT may be caused by increased contraction of a muscle during exercise. Because when there is muscle contraction during exercise there is an increase in energy demand, causing the muscles to work harder in supplying energy (Melinda, 2004). Meeting energy needs during exercise can increase muscle contraction which is characterized by increased IL-6 secretion. Muscle secreted IL-6 helps maintain metabolic homeostasis (Febbraio and Pedersen, 2002) which play a role in regulating metabolism in adipose tissue, skeletal muscle and liver (Lutoslawska, 2012). Adipose and liver tissue contribute to maintain glucose homeostasis, inducing lipolysis and inhibiting the effects of pro-inflammatory cytokines such as TNF- $\alpha$, thus protecting against insulin resistance and atherosclerosis (Pedersen et al., 2001). During exercise will increase the consumption of muscle subster and increase glycogen and fat oxidation, thereby activating lipolysis in adipose tissue (Yazdani et al., 2013). Lipolysis activates in fat tissue to provide energy to muscles, but also has a positive effect on intramuscular fat utilization. According to Lutoslawska (2012) IL-6 also stimulates cell satellite and muscle hypertrophy and muscle repair, because it is an important molecule of muscle hypertrophy by controlling cell satellite proliferation and myonuclear accretion mediated by the activation of signal transducers and activators of transcription 3 (STAT3) (Serrano et al., 2008), glycogen synthesis through phosphatidylinositol-3 kinase (PI3K) (Al-Khalili et al., 2006). In addition, IL-6 can also affect lipid metabolism (Pedersen and Febbraio, 2005) through the mechanism of mitogenactivated protein kinase (MAPK) in skeletal muscle (Al-Khalili et al., 2006). High levels of IL-6 in HIT may also occur due to a mechanism between the muscles and the brain. 


\section{STRADA Jurnal Ilmiah Kesehatan}

DOI: $10.30994 /$ sjik.v9i1.272

ISSN: 2252-3847 (print); 2614-350X (online)

Vol.9 No.1. May 2020. Page.93-101

According to Pedersen and Febbraio (2005) IL-6 connects the mechanism for direct interaction between muscle and brain, so it has a lot of effects on brain function, IL-6 also crosses the blood brain barrier so that it not only affects metabolism during exercise, but also regulates muscle activity, affects mood, performance and cognitive function. On the other hand, high levels of IL-6 in HIT may be caused by stress levels experienced. Stress affects the activation of the Hypothalamus-Pituitary-Adrenal axis (HPA-axis) axis (Clark and Mach, 2016), which its functions to stimulate an increase in Corticotrophin-Releasing Hormone (CRH) (Sugiharto, 2012) and secrete the hormone Adenocortico-tropin Hormone (ACTH) (Powers and Howley, 2015). ACTH secretion stimulates the secretion of the hormone cortisol (Usui et al., 2011). Cortisol causes an increase in cytokine secretion (Walsh et al., 2011), as an inflammatory mediator (Indra, 2007). One of the inflammatory mediator cytokines is IL-6. IL-6 is a major endocrine cytokine that has a major role in immune stimulation, especially in inflammatory stress (Tsigos and Chrousos, 2002).

\section{CONCLUSION}

Moderate intensity training by listening to music tempo $160 \mathrm{bpm} / \mathrm{min}$ significantly decreases IL-6 levels. Moderate intensity training with listening to music tempo $160 \mathrm{bpm} /$ min and performed it for 15-30 minutes with a frequency of 3 times / week for 10 weeks has a positive effect in reducing inflammation compared with high intensity training and control. Based on the results of the study it is recommended to do further research by adding several other parameters such as tumor necrosis factor- $\alpha$ (TNF- $\alpha$ ), interleukin- $1 \beta$ (IL-1 $\beta)$, interleukin-1 $\alpha$ (IL-1 $\alpha)$ and interleukin-8 (IL-8 ) as an indicator of proinflammation, while interleukin-1 (IL-1), interleukin-1ra (IL-1ra) and interleukin-10 (IL-10) as indicators of anti-inflammatory, cortisol, blood glucose and muscle protein.

\section{REFERENCES}

Ahmadiasl, N., Hesari, F.S. and Sales, E.K. 2014. Cerebellum and Reelin under chronic treadmill exercise conditions in malerats. International Journal of Advanced Biological and Biomedical Research, 2(1): 170-175.

Ali, K.H., Arman, J., Salar, A., Salah, H., Samaneh, K.A., Glareie, S. and Zari, S. 2014. The Effect on one session intense anaerobic exercise (Bruce test) on serum level of IL-6 and IL-33 in volybalist athletes. Annals of Biological Research, 5(2): 99-104.

Al-Khalili, L., Bouzakri, K., Glund, S., Lönnqvist, F., Koistinen, H.A. and Krook, A. 2005. Signaling Specificity of Interleukin-6 Action on Glucose and Lipid Metabolism in Skeletal Muscle. Molecular Endocrinology, 20(12): 3364-3375. https://doi.org/10.1210/me.2005-0490.

Bakhtiar, R., Nikbakht, H. and Mohan, M. 2012. The Effect of Relaxing Music on Change in Blood Lactate Level During Recovery Following a Maximal Exercise Session in Young Female Athletes. International Journal of Sport Studies, 2(9): 432-435.

Bruunsgaard, H., Galbo, H., Halkjaer-Kristensen, J., Johansen, T.L., MacLean, D.A. and Pedersen, B.K. 1997. Exercise-Induced Increase in Serum Interleukin-6 in Humans is Related to Muscle Damage. The Journal of Physiology, 499(3): 833-841. https://doi.org/10.1113/jphysiol.1997.sp021972.

Chanda, M.L. and Levitin, D.J. 2013. The Neurochemistry of Music. Trends in Cognitive Sciences, 17 (4): 179-194. https://doi.org/10.1016/j.tics.2013.02.007.

Chung, E. and Diffee G.M. 2012. Moderate Intensity, but Not High Intensity, Treadmill Exercise Training Alters Power Output Properties in Myocardium From Age Rats. 


\section{STRADA Jurnal Ilmiah Kesehatan}

DOI: $10.30994 /$ sjik.v9i1.272

ISSN: 2252-3847 (print); 2614-350X (online)

Vol.9 No.1. May 2020. Page.93-101

Balke Biodynamics Laboratory, Department of Kinesiology, 67(11): 1178-1187. https://doi.org/10.1093/gerona/gls146.

Clark, A., and Mach, N. 2016. Exercise induced stress behavior, gutmicrobiota brain axis and diet: a systematic review for athletes. Journal of the International Society of Sports Nutrition, 13: 1-21.

Daloii, A.A., Ahmad, A. and Sorati, H.A. 2014. Serum Interleukin 6 before and Immediately after a Moderate Exercise in Asthma Patients. Biological Forum An International Journal, 6(2): 377-381.

Djohan. 2010. Respons Emosi Musikal. Bandung: Lubuk Agung.

Eaton, M., Granata, C., Barry, J., Safdar, A., Bishop, D. and Little, J.P. 2018. Impact of a Single Bout of High-Intensity Interval Exercise and Short-Term Interval Training on Interleukin-6, FNDC5 and METRNL mRNA Expression in Human Skeletal Muscle. Journal of Sport and Health Science, 7(2): 191-96.

Febbraio, M. and Pedersen, B.K. 2002. Muscle-derived Interleukin-6: Mechanisms for Activation and Possible Biological Roles. The FASEB Journal. 16(11): 1335-1347. https://doi.org/10.1096/fj.01-0876rev.

Gleeson, M. 2005. Immune Function and Exercise. European Journal of Sport Science, 4(3): 52-66. https://doi.org/10.1080/17461390400074304.

Indra, M.R. 2007. Fisiologi Kardiovaskular. Malang: Laboratorium Ilmu Faal Fakultas Kedokteran Universitas Brawijaya.

Kisan, R., Kisan, S.R., Anitha and Chandrakala. 2012. Treadmill and Bicycle Ergometer Exercise: Cardiovascular Response comparison. Global Journal of Medical research, 12(5): 23-26.

Lyngso, D., Simonsen, L. and Bulow, J. 2002. Interleukin-6 Production in Human Subcutaneous Abdominal Adipose Tissue: The Effect of Exercise. Department of Clinical Physiology, Bispebjerg Hospital, DK-2400 Copenhagen NV, Denmark. $\begin{array}{lllll}\text { Journal of } & \text { Physiology. } & 543 & \text { (1): } & 373-378 .\end{array}$ https://doi.org/10.1113/iphysiol.2002.019380.

Lee, I-M. and Paffenbarger, R.S. 2000. Associations of Light, Moderate, and Vigorous Intensity Physical Activity with Longevity: The Harvard Alumni Health Study. American Journal of Epklemiotogy, 151(3): 293-299. https://doi.org/10.1093/oxfordjournals.aje.a010205.

Lutoslawska, G. 2012. Interleukin-6 as an Adipokine and Myokine: The Regulatory Role of Cytokine in Adipose Tissue and Skeletal Muscle Metabolism. Human Movement, 13 (4): 372-379. https://doi.org/10.2478/v10038-012-0045-y.

Markovitch, D., Tyrrell, R.M. and Thompson, D. 2008. Acute Moderate-Intensity Exercise in Middle-Aged Men Has Neither an Anti- Nor Proinflammatory Effect. J Appl Physio, 105: 260-265.

Mastorakos, G., Pavlatou, M., Diamanti-Kandarakis, E. and Chrousos, G.P. 2005. Exercise and the Stress System. Hormones, 4(2): 73-89.

Melinda, M.M. 2004. Nutrition and Physical Activity: Fueling the Active Individual. President's Council on Physical Fitness and Sports Research Digest, 5(2): 1-8

Mohammadi, H.R., Taghian, F., Khoshnam, M.S., Rafatifar, M. and Sabagh, M. 2011. The Effect of acute physical exercise on serum IL6 and CRP levels in healthy nonathlete adolescents. Journal of Jahrom University of Medical Sciences, 9(2): 27-33. 


\section{STRADA Jurnal Ilmiah Kesehatan}

DOI: $10.30994 /$ sjik.v9i1.272

ISSN: 2252-3847 (print); 2614-350X (online)

Vol.9 No.1. May 2020. Page.93-101

Mohammadi, H.R., Khoshnam, E., Khoshnam, M.S., Karampour, E. and Jahromi, F.Z. 2012. The Effect of Regular Exercise on CRP and IL-6 in Obese Men. $A d v$. Environ. Biol, 6(12): 3065-3068.

Moylan, S., Eyre, H., Maes, M., Bauneb, B., Jacka, F. and Berk, M. 2013. Exercising The Worry Away: How Inflammation, Oxidative And Nitrogen Stress Mediates The Beneficial Effect Of Physical Activity On Anxiety Disorder Symptoms And Behaviours. Neuroscience and Biobehavioral Reviews, 37(4): 573-584. https://doi.org/10.1016/j.neubiorev.2013.02.003.

Mueller, P.J. 2007. Activity-Dependent Plasticity in Central Homeostatic Systems: Exercise Training And Sympathetic Nervous System Activity: Evidence For Physical Activity Dependent Neural Plasticity. Clinical and Experimental Pharmacology and Physiology, 34(4): 377-384. https://doi.org/10.1111/j.14401681.2007.04590.x.

Neto, J.G., Antunes, B.M.M., Campos, E., Rodrigues., J., Ferrari., G.D., Neto, J.C.R., Junior, C.R.B., and Lira, F.S. 2016. Impact Of Long-Term High-Intensity Interval And Moderate-Intensity Continuous Training On Subclinical Inflammation In Overweight/Obese Adults. Journal of Exercise Rehabilitation, 12(6): 575-580. https://doi.org/10.12965/jer.1632770.385.

Nieman, D.C. 2012. Clinical implications of exercise immunology. Journal of Sport and Health Science, 1(1): 12-17. https://doi.org/10.1016/j.jshs.2012.04.004.

Oberbach, A., Lehmann, S., Kirsch, K., Krist, J., Sonnabend, M., Linke, A., Tonjes, A., Stumvoll, M., Bluher, M. and Kovacs, P. 2008. Long-Term Exercise Training Decreases Interleukin-6 (IL-6) Serum Levels in Subjects With Impaired Glucose Tolerance: Effect Of The K174G/C Variant in IL-6 Gene. European Journal of Endocrinology, 159: 129-136. https://doi.org/10.1530/EJE-08-0220.

Okada, K., Kurita, A., Takase, B., Otsuka, T., Kodani, E., Kusama, Y., Atarashi, H. and Mizuno, K. 2008. Effects of Music Therapy on Autonomic Nervous System Activity, Incidence of Heart Failure Events and Plasma Cytokine and Catecholamine Levels in Elderly Patients With Cerebrovascular Disease and Dementia. Int Heart J, 50(1): 1-7.

Ostrowski, K., Rohde, T., Asp, S., Schjerling, P. and Pedersen, B.K. 1999. Pro- and antiinflammatory cytokine balance in strenuous exercise in humans. The Journal of Physiology, 15(515): 287-291. https://org.doi/10.1111/j.1469-7793.1999.287ad.x.

Pedersen, B., Steensberg, A. and Schjerling, P. 2001. Muscle-derived Interleukin-6: Possible Biological Effects. Journal of Physiology, 536(2): 329-337. https://doi.org/10.1111/j.1469-7793.2001.0329c.xd.

Pedersen, B.K. and Febbraio, M. 2005. Muscle-Derived Interleukin-6-A Possible Link Between Skeletal Muscle, Adipose Tissue, Liver and Brain. Brain Behav Immun, 19(5): 371-376. https://doi.org/10.1016/j.bbi.2005.04.008.

Petersen, A.M.W. and Pedersen, B.K. 2005. The Anti Inflammatory Effect of Exercise. Journal of Applied Physiology, 98(4): 1154-1162. https://doi.org/10.1152/japplphysiol.00164.2004.

Petersen, A.M.W. and Pedersen, B.K. 2006. The Role of IL-6 in Mediating The Anti Inflammatory Effects of Exercise. Journal of Physiology and Pharmacology, 57(10): 43-51. 


\section{STRADA Jurnal Ilmiah Kesehatan}

DOI: $10.30994 /$ sjik.v9i1.272

ISSN: 2252-3847 (print); 2614-350X (online)

Vol.9 No.1. May 2020. Page.93-101

Powers, S.K. and Howley, E.T. 2015. Exercise Physiology. Theory and Application to Fitness and Performance Tenth Edition. Hormonal Responses to Exercise. California: The McGrawHill Companies, Inc.

Savitha, D., Sejil, T.V., Rao, S., Roshan, C.J. and Avadha, S.T. 2013. The Effect of Vocal and Instrumental Music on Cardiorespiratory Variabels, Energy Expenditure and Exertion Levels During Sub maximal Treadmill Exercise. Indian J Physiol Pharmacol, 57(2): 159-168.

Serrano, A.L., Baeza-Raja, B., Perdiguero, E., Jardí, M. and Muñoz-Cánoves, P. 2008. Interleukin-6 Is an Essential Regulator of Satellite Cell-Mediated Skeletal Muscle Hypertrophy. Elsevier Inc, 7(1): 33-44. https://doi.org/10.1016/j.cmet.2007.11.011.

Shaikh, P.Z. 2011. Cytokines \& Their Physiologic and Pharmacologic Functions in Inflammation. International Journal of Pharmacy \& Life Sciences, 2(11): 12471263.

Shojaei, E.A., Farajov, A. and Jafari, A. 2011. Effect of Moderate Aerobic Cycling on Some Systemic Inflammatory Markers in Healthy. International Journal of General Medicine, 2011(4): 79-84. https://doi.org/10.2147/IJGM.S15065.

Stefano, G.B., Zhu, W., Cadet, P., Salamon, E. and Mantione, K.J. 2004. Music alters constitutively expressed opiate and cytokine processes in listeners. Med Sci Monit. 10(6): 18-27.

Starkweather, A.R. 2007. The Effects of Exercise on Perceived Stress and IL-6 Levels Among Older Adults. Biological Research For Nursing, 9(3): 186-194. https://doi.org/10.1177/109980046295990.

Sugiharto. 2009. Physiological Effects of Music during Exercise Secretion of Hormones Cortisol and Endorphins. Folia Medica Indonesiana, 45(2): 121-129.

Sugiharto. 2012. Fisioneurohormonal Pada Stresor Olahraga. Jurnal Sains Psikologi, 2(2): 54-66.

Terry, P.C. and Karageorghis, C.I. 2006. Psychophysical Effects of Music in Sport and Exercise: An update Theory, Research and Application. 415-419.

Tsigos, C. and Chrousos, P.G. 2002. Hypothalamic-Pituitary-Adrenal Axis, Neuroendocrine Factors and Stress. Journal of Psychosomatic Research, 53(4): 865-871. https://doi.org/10.1016/s0022-3999(02)00429-4.

Uchakin, P.N., Gotovtseva, P.E., Gundersen, S.J. 2003. Immune and Neuroendocrine Alterations in Marathon Runners. Journal of Applied Research, 3(4): 483-494.

Usui, T., Yoshikawa, T., Ueda, S.Y., Katsura, Y. Orita, K. and Fujimoto, S. 2011. Effects Of Acute Prolonged Strenuous Exercise On The Salivary Stress Markers And Inflammatory Cytokines. Journal of Physical Fitness and Sports Medicine, 60: 295-304.

Walsh, N.P., Gleeson, M., Shephard, R.J., Gleeson, M., Woods, J.A., Bishop, N.C., Fleshner, M., Green, C., Pedersen, B.K., Hoffman-Goetz, L., Rogers, C.J., Northoff, H., Abbasi, A. and Simon, P. 2011. Immune Functions and Exercise. Exercise Immunology Review, 7: 6-63.

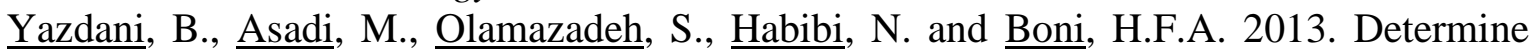
Changes of Plasma Glucose of Trained and Untrained Male Rats After Eight Week Endurance Exercise. European Journal of Experimental Biology, 3(3): 267-272.

Zhang, Z., Zhang, L. and Xu, J. 2007. The effects of different exercise training mode on interleukin. Life Science Journal, 4(3): 82-86. 